\title{
O USO DOS GÊNEROS TEXTUAIS NO ENSINO DOS QUATRO EIXOS DA LÍNGUA PORTUGUESA ${ }^{1}$
}

\author{
THE USE OF TEXT GENRES IN THE TEACHING \\ OF THE FOUR AXES OF THE PORTUGUESE LANGUAGE
}

\author{
Ariele Helena Holz Nunes | Lattes | holz.ariele@gmail.com \\ Universidade Federal de Santa Catarina
}

Resumo: Este estudo tem como objetivo analisar o uso dos gêneros textuais como ferramenta de ensino dos quatro eixos da Língua Portuguesa. Para tanto, o apoio teórico foi buscado em Bunzen (2007), Dolz e Schneuwly (2004), Marcuschi (2002), entre outros. Os caminhos metodológicos foram trilhados através da aplicação de um instrumento de pesquisa - um questionário com questões objetivas e dissertativas - com alunos do $1^{\circ} \mathrm{e}$ $2^{\circ}$ ano do ensino médio de uma escola pública da cidade de Joinville/SC. Considerando que o trabalho com os gêneros textuais está previsto nos documentos oficiais de educação, foi questionado, especialmente, como os gêneros são abordados no ensino da Língua Portuguesa. A ideia central era investigar se os estudantes reconhecem a utilização dos gêneros textuais durante o ensino de Língua Portuguesa ou se esta noção de ensino e aprendizagem voltada aos textos na modalidade escrita e oral ainda é abstrata. Partindo desse pressuposto, mediante a análise dos dados, os resultados sugerem que o ensino de língua materna pautado nos gêneros textuais tem ganhado as salas de aula, embora as suas idealizações já tenham ocorrido há algumas décadas.

Palavras-chave: Gêneros textuais. Ensino. Língua Portuguesa.

\begin{abstract}
This study is aimed at analysing the use of text genres as a teaching instrument of the four axes of the Portuguese Language. For this purpose, the theoretical frame was searched in Bunzen (2007), Dolz and Schneuwly (2004), Marcuschi (2002), among others. The methodological paths followed the administration of a questionnaire with closed and open questions for students from the 1st and 2nd year of high school in a public school in the city of Joinville, state of Santa Catarina. Considering that the work

\footnotetext{
${ }^{1}$ Este artigo é fruto das discussões propostas na disciplina de Linguística Aplicada à Língua Portuguesa, oferecida pelo curso de licenciatura em Letras - Língua Portuguesa (UNIVILLE) e ministrada pela professora Dra. Rosana Mara Koerner, a quem dedico o meu singelo agradecimento pela partilha de conhecimentos e pelas orientações de leitura e escrita.
} 
with text genres is stated in the official educational documents, it was questioned, especially, how genres are discussed in Portuguese Language Teaching. The central idea was to investigate whether students recognize the use of textual genres during the teaching of Portuguese or whether this notion of teaching and learning focused on texts in written and oral form is still abstract. Based on this assumption, the results suggest that mother tongue teaching based on text genres has been included in the Portuguese languge teaching, even though its idealizations had occurred a few decades ago.

Keywords: Text Genres. Teaching. Portuguese Language.

\section{Introdução}

$\mathrm{Na}$ contemporaneidade, o sistema educacional brasileiro conta com documentos oficiais norteadores da educação básica, os quais abordam questões importantes para o currículo de diferentes áreas de ensino. No que concerne ao ensino da Língua Portuguesa, há uma preocupação com o desenvolvimento de um processo de ensino/aprendizagem voltado ao exercício da cidadania, em que sejam criadas condições para que o aluno construa a sua competência discursiva. À vista disso, a escola deve organizar atividades curriculares que promovam o trabalho com a língua e a linguagem, fazendo com o que o corpo discente se aproprie de conhecimentos linguísticos relevantes para a vida em sociedade.

Os Parâmetros Curriculares Nacionais (1998) já sugeriram, há duas décadas, que o ensino da Língua Portuguesa deveria apresentar como centralidade a multiplicidade de textos, de modo que fossem trabalhados em sala de aula diferentes tipos de gêneros, pertencentes às variadas esferas de comunicação. Dando continuidade às idealizações dos PCN (1998), a Base Nacional Comum Curricular (2018) apresenta em seu aporte teórico a concepção de eixos de ensino para se referir ao componente de Língua Portuguesa, colocando em pé de igualdade a leitura, a produção escrita, a oralidade e a análise linguística e, simultaneamente, apontando um mesmo objetivo a todas essas vertentes: o texto.

Neste artigo, discute-se o uso dos gêneros textuais no ensino dos quatro eixos da Língua Portuguesa, buscando apresentar reflexões acerca de três questões motivadoras: a) Como os gêneros textuais são abordados no ensino dos quatro eixos da Língua Portuguesa?; b) Quais as metodologias/estratégias utilizadas pelo professor para desenvolver o trabalho com os gêneros textuais no ensino de Língua Portuguesa; c) Os alunos reconhecem o trabalho com os gêneros no ensino da leitura, gramática, escrita e oralidade durante as aulas de Língua Portuguesa? 
Para tanto, realizou-se uma pesquisa qualiquantitativa, com a aplicação de um questionário com questões objetivas e dissertativas sobre o uso dos gêneros textuais no processo de ensino e aprendizagem da Língua Portuguesa. $\mathrm{O}$ instrumento foi aplicado com alunos do $1^{\circ}$ e $2^{\circ}$ ano do ensino médio de uma escola pública da cidade de Joinville/ SC. A pesquisa ocorreu em paralelo ao período de Estágio Curricular Obrigatório da pesquisadora durante a graduação em Letras, sendo realizado na mesma instituição, além de seguir a documentação prevista nesse processo formativo. Igualmente, foi realizada a revisão da Literatura, tendo como autores fundantes: Bezerra (2002), Bunzen (2007), Dolz e Schneuwly (2004), Marcuschi (2002), Mendonça (2007), Rojo e Jurado (2007), entre outros.

Consideradas essas questões, acresce mencionar que este trabalho encontra sua significância na tentativa de compreender como ocorre o cruzamento entre os eixos formadores do ensino da Língua Portuguesa e os gêneros textuais. A investigação também encontra seu propósito ao observar se a realidade do ensino de língua condiz com as propostas dos documentos oficiais de educação, que visam colocar os quatro eixos de ensino no mesmo patamar de importância e abrangência no espaço escolar. Dentre tantas questões, pode-se dizer que o diferencial do trabalho frente aos demais estudos sobre gêneros textuais se encontra na tentativa de trazer para o debate a voz do aluno e a sua percepção sobre o uso dos gêneros textuais no ensino de Língua Portuguesa. Houve a iniciativa de demonstrar se os estudantes reconhecem o uso dos gêneros textuais como uma ferramenta de ensino e aprendizagem ou se esta concepção ainda é abstrata para os informantes. Partindo das observações realizadas em sala de aula, como parte do estágio curricular obrigatório, o instrumento foi pensado e estruturado com vistas às práticas do docente, evocando, assim, as ações realizadas pelo professor em prol do ensino através dos gêneros textuais. Em função disso, abriu-se espaço e a possibilidade de os estudantes reconhecerem, efetivamente, esse uso, uma vez que os gêneros e as abordagens utilizadas pelo professor foram mencionadas no instrumento de pesquisa.

\section{Algumas considerações}

Na tentativa de conceituar o termo gêneros textuais, recorre-se a Marcuschi (2002), que os define como ações sociodiscursivas incontáveis que servem para agir sobre o mundo e para nomear o mundo, constituindo-o de alguma maneira. Em outras palavras, os gêneros são fenômenos históricos, que estabelecem ligação com a vida cultural e social, uma vez que servem para atender a alguma atividade sociocomunicativa: 
[...] gêneros textuais surgem, situam-se e integram-se funcionalmente nas culturas em que se desenvolvem. Caracterizam-se muito mais por suas funções comunicativas, cognitivas e institucionais do que por suas peculiaridades linguísticas e estruturais. São de difícil definição formal, devendo ser contemplados em seus usos e condicionamentos sociopragmáticos caracterizados como práticas sociodiscursivas. Quase inúmeros em diversidade de formas, obtêm denominações nem sempre unívocas e, assim como surgem, podem desaparecer (MARCUSCHI, 2002, p. 20).

Acresce mencionar que, apesar de serem denominados por alguns teóricos como famílias de textos com características comuns, embora heterogêneas, os gêneros qualificam-se principalmente, na voz de Bakhtin (1997), como tipos "relativamente estáveis de enunciados”. Eles são eventos linguísticos que atendem a alguma esfera comunicativa, mas não se tornam similares por sua estrutura composicional, e sim pelo seu caráter sociodiscursivo, pelo seu uso, função e determinação na sociedade que necessita de uma forma pela qual se expressar, para realizar objetivos peculiares em situações discursivas.

Dessa forma, compete ao professor de língua realizar atividades que desenvolvam a competência discursiva do aluno tanto na modalidade oral quanto escrita, já que os gêneros se manifestam em ambos os domínios comunicativos, desde os mais formais aos informais, inclusive aqueles que circulam na vida cotidiana. $\mathrm{O}$ trabalho com gêneros em sala de aula possibilita que o aluno produza e reflita sobre os diversos usos da linguagem, identificando a importância e as características dos gêneros que circulam nos dois âmbitos: oral e escrito.

Retomando a questão da diversidade dos gêneros, Dolz e Schneuwly (2004) apontam para a sua utilização nas aulas de português, sendo esse processo uma mera aplicação de sequências estereotipadas que formam produtos culturais da escola. Dessa forma, o alunado acaba produzindo textos que se tornam eficientes apenas no âmbito escolar, fazendo com os gêneros percam seu caráter comunicativo e ganhem a função de "instrumento para desenvolver e avaliar, progressiva e sistematicamente, as capacidades de escrita dos alunos" (DOLZ e SCHNEUWLY, 2004, p.77).

Assumindo o mesmo posicionamento teórico, Marcuschi (2002, p.36) escreve:

[...] os gêneros que aparecem nas seções centrais e básicas, analisados de maneira aprofundada são sempre os mesmos. Os demais figuram apenas para "enfeite" e até para distração dos alunos. São poucos os casos de tratamento dos gêneros de maneira sistemática. Lentamente, surgem novas perspectivas e novas abordagens que incluem até mesmo aspectos da oralidade. 
Para além do que foi mencionado, há de ser considerado que, na BNCC (2018), o ensino da Língua Portuguesa articula-se através de quatro eixos de ensino: a leitura, a produção escrita, a oralidade e a análise linguística. O primeiro compreende as práticas de linguagem que emergem do contato do leitor com o texto escrito e imagético e suas interpretações. A produção escrita está relacionada com o trabalho de reflexão acerca das situações sociais em que se escrevem textos. Em relação à oralidade, o movimento de investigação é voltado para a imensa variedade da língua na modalidade oral. Já a análise linguística está envolta por uma perspectiva funcional das regras e convenções do uso formal da língua.

Sendo assim, no que concerne ao ensino da oralidade, Melo e Cavalcante (2007) sinalizam a ênfase que se dá para a escrita no contexto escolar, fazendo com que a oralidade fique praticamente à margem das aulas, em especial as de português. Diante dessa premissa, faz-se necessário mencionar que esse cenário está sendo modificado gradativamente dadas as iniciativas recentes de a oralidade ser inserida nos livros e demais materiais didáticos.

Entretanto, a dificuldade de situar a oralidade como um objeto de ensino/aprendizagem ainda é perceptível, pois não se sabe onde e como inserir atividades com os gêneros orais no ambiente escolar. Em decorrência disso, é comum os docentes abordarem as práticas orais por meio de um exercício comparativo com a escrita ou de diferenciação entre a língua falada coloquial e a língua falada formal. Não há uma preocupação em estruturar os gêneros da tradição oral. Além disso, a consciência de que as mesas redondas, os seminários, os debates e as entrevistas fazem parte desse meio, servindo de instrumento para se trabalhar com a oralidade em sala de aula, é quase inexistente.

Infelizmente, a crença de que o corpo discente domina melhor os gêneros orais do que os escritos por estar em constante contato com a oralidade resulta na falta de orientação adequada nas atividades desenvolvidas através da fala e, também, numa avaliação errônea dos estudantes, já que eles acabam não atingindo as expectativas ou não sobressaindo a estas:

[...] no geral, as atividades com gêneros orais, quando muito, fornecem ao aluno apenas o nome do gênero a ser produzido, esperando que ele saiba desenvolver seu trabalho. [...] Ao final, vamos avaliando mal o aluno que não soube apresentar bem o trabalho oralmente ou atribuímos a nota exclusivamente (ou com peso maior) pela avaliação da parte escrita, já que é frequente um texto escrito acompanhar uma apresentação oral (MELO E CAVALCANTE, 2007, p. 184). 
Consequentemente, a noção de oralidade como uma das vertentes de ensino da língua materna ainda é muito primitiva, colocando-a como um resíduo diante dos outros eixos que compreendem o currículo da Língua Portuguesa. Direcionando melhor essa afirmação, Melo e Cavalcante (2007, p.182) pontuam que, “[...] se o conhecimento linguístico, produção textual e leitura vão bem, o tratamento da oralidade no ensino de língua ganha menos importância”. Assim sendo, o trabalho com a oralidade demanda novas estratégias e metodologias que atinjam o aluno, fazendo com que ele compreenda, se interesse e investigue a imensa riqueza e variedade da língua na modalidade oral.

Nas lições de Bunzen (2007), assim como a oralidade, nos primórdios (entre os séculos XVIII e XX), a escrita também não recebeu o devido reconhecimento, sendo posta em terceiro plano, já que o destaque e a preocupação do ensino de Língua Portuguesa eram o desenvolvimento da capacidade leitora e o domínio de regras gramaticais.

A preparação do aluno enquanto sujeito-escritor estava condicionada às disciplinas de retórica, poética e literatura nacional, em que se ensinava a técnica de "composição", que consiste na escrita de textos "[...] a partir de figuras ou títulos dados tendo como base os textos-modelos apresentados pelo professor" (BUNZEN, 2007, p.142). Almejava-se que o estudante possuísse uma escrita de qualidade, produzindo sempre um "produto final", ou seja, um texto essencialmente clássico e bem escrito.

O ensino da escrita enquanto mera assimilação de técnicas, modelos e padrões passa a ser modificado a partir das décadas de 1960 e 1970. Nesse período, surge a ideia de "redação escolar", iniciando um lento processo que visa trabalhar com a criatividade do aluno, o qual se fortalece por meio da efetivação da LDB no 5692/71. Isso posto, faz-se necessário relatar que o saber sobre a língua deixa de ser o centro e novos fins didáticos emergem: "[...] os objetivos passam a ser pragmáticos e utilitários, trata-se de desenvolver e aperfeiçoar os comportamentos do aluno como emissor e recebedor de mensagens, através da utilização e compreensão de códigos diversos - verbais e não verbais" (BUNZEN, 2007, p.144).

Ainda nesse âmbito, apesar de a redação ser posta como um possível avanço no ensino da escrita, recebeu muitas críticas relacionadas à sua validade enquanto objeto de ensino. Seguindo as teorizações de Bunzen (2007) quanto ao uso das redações, há algumas constatações: a) o ensino de redação como um mero exercício escolar, cujo objetivo principal é apresentar os erros gramaticais cometidos pelo aluno; b) um trabalho com a escrita sem função; c) a escrita do aluno para cumprir uma exigência do professor ou treinar para passar em concursos públicos/vestibular. 
Diante desse cenário, como anteriormente mencionado, no final dos anos 1980 e início dos anos 1990, surge um movimento em prol do ensino da escrita. Há um novo ideal, um direcionamento ao trabalho com os gêneros textuais na perspectiva do letramento: “[...] os alunos não deveriam produzir mais redações, meros produtos escolares, mas textos diversos que se aproximassem dos usos extraescolares, com função específica e situada dentro de uma prática social escolar" (BUNZEN, 2007, p.149).

Ao tomar os gêneros como objetos de ensino, o docente está assumindo o desafio de encaminhar a aprendizagem da língua escrita para uma perspectiva em que se trabalhe com diversos textos, estilos, suportes e meios de circulação nas diversas esferas comunicativas. Segundo Bunzen (2007, p.158): "Nessa direção, as práticas de leitura e de produção de textos em gêneros diversos que fazem parte do cotidiano dos alunos nos diversos espaços de socialização podem ser legitimadas na escola”. Portanto, o ensino da escrita pautado no trabalho com os gêneros textuais surge como uma iniciativa de desenvolver a autonomia dos alunos, que já produzem textos em diversos gêneros, mas que ainda repudiam o ato de escrever.

Com relação ao ensino da gramática, Mendonça (2007, p.74) aponta para uma nova prática que vem se estabelecendo nas aulas de Língua Portuguesa, com o propósito de se ensinar gramática por uma outra perspectiva, a da análise linguística. Apesar de ser entendida como “[...] o ensino da gramática contextualizada”, a análise linguística está longe de ter essa configuração.

A gramática contextualizada é delimitada como uma "metodologia renovada no ensino de língua materna”, em que se trabalha com o texto na centralidade. No entanto, o que acontece é a utilização do texto a serviço da gramática tradicional, já que se propõem exercícios de: retirada dos adjetivos do texto, análise sintática de períodos do texto, destaque e busca de algum tipo de verbo ou outra classe gramatical. Verifica-se, em Mendonça (2007, p.74), que a dita gramática contextualizada realiza a manutenção da gramática tradicional de forma mascarada:

\footnotetext{
A única diferença entre o trabalho tradicional com a gramática e este, com a dita "gramática contextualizada", é que as frases não mais são apresentadas de forma isolada, pois fazem parte de um texto; porém isso não significa que se trabalhe com o texto em si, com sua articulação interna, ou com o gênero e seu funcionamento nas práticas sociais.
}

Assim sendo, faz-se necessário que não se tenha entendimento errôneo acerca das duas formas de ensino, uma vez que a prática de análise linguística não significa apenas 
ensinar a gramática por outro ângulo, valendo-se de outras metodologias, mas sim mudar a concepção de linguagem e de como o ensino desse eixo da Língua Portuguesa deve ser articulado.

Para Mendonça (2007), há grandes diferenças entre o ensino tradicional da gramática e a prática de análise linguística. Enquanto o tradicionalismo enxerga a língua como um sistema acabado, uma estrutura inflexível, a prática de análise linguística concebe a língua como uma ação interlocutiva, situada aos falantes. A primeira tem centralidade na norma padrão; a segunda, nos efeitos de sentido. De um lado, exercícios estruturais; do outro, a preferência por questões abertas, de pesquisa, reflexão. A gramática normativa com a fragmentação dos eixos de ensino (leitura, produção textual, gramática) e a análise linguística, com a integração dos eixos de ensino, visando um processo de ensino e aprendizagem complementar.

Portanto, evidencia-se que a análise linguística parte do pressuposto de que:

[...] a linguagem não é uma estrutura dada, acabada, mas uma forma de (inter)ação social, que funciona segundo certas condições de produção dos discursos - interlocutores, situação sociocomunicativa, gênero, forma de circulação, etc. Transportada para o âmbito da escola, essa perspectiva considera a construção de efeitos de sentido como o ponto central das discussões a serem efetivadas em sala de aula, deslocando profundamente a organização dos conteúdos e competências no ensino de língua materna em vários aspectos (MENDONÇA, 2007, p.76).

Ademais, a análise linguística possibilita o ensino da gramática por meio dos gêneros textuais, trabalhando com a função comunicativa do texto e não mais com a fixação de regras e exercícios repetitivos. Trata-se de refletir sobre o uso adequado do registro, dos recursos linguísticos adotados em cada situação comunicativa.

Desse modo, cabe ao professor de língua articular os conhecimentos macro, a função do gênero, a sua estrutura, suporte, circulação nas esferas sociais, os interlocutores; e os conhecimentos micro, a forma de construção do texto, os mecanismos linguísticos que devem ser utilizados, a escolha das palavras, expressões, a organização dos períodos etc. Há uma necessidade da realização desse processo, uma vez que a organização micro, ou seja, o arranjo dos elementos da língua no texto, dá embasamento para que o gênero exerça o seu papel social. Assim, “[...] as escolhas linguístico-discursivas presentes num dado gênero não são aleatórias, mas ali estão para permitirem que um gênero funcione socialmente” (MENDONÇA, 2007, p.77). 
Por conseguinte, pode-se acentuar que o principal objetivo da adoção da análise linguística durante as aulas de português é a busca pela reflexão daquilo que se aprende, do seu objeto de estudo. Em outras palavras, considerando que o ensino de gramática pela própria gramática não acarreta grandes reflexões sobre o uso real da língua, a prática de análise linguística busca trabalhar, através dos gêneros, os diversos recursos gramaticais e estratégias textuais para que o alunado aprenda a reconhecer os usos da linguagem no meio social. Nesse sentido, o tratamento superficial e isolado desses elementos gramaticais não é suficiente para a compreensão dos diferentes papéis que a gramática desempenha na produção de sentido dos diferentes gêneros.

Quanto ao ensino de leitura, fazendo alusão ao processo de formação da disciplina de Língua Portuguesa novamente, há de ser constatado que, para Rojo e Jurado (2007), a leitura, até a metade do século XX, era um processo bastante primitivo, já que envolvia apenas capacidades de decodificação. O aluno não construía sentidos a partir do texto, assim como não dialogava ou fazia associações com outros autores, ou desenvolvia alguma consciência crítica. Acessava-se o texto apenas para transformar grafemas em fonemas, não se faziam grandes reflexões sobre o que se lia.

Atualmente, os documentos oficiais de educação trazem um novo objetivo para o ensino da leitura, sendo o principal a construção de leitores críticos, os quais conseguem se posicionar enquanto sujeitos atuantes na sociedade. Nesse sentido, Rojo e Jurado (2007, p.40) escrevem:

[...] ler é dialogar com a consciência do autor, com outros enunciados e vozes, não decifrando, mas produzindo sentidos com os conhecimentos que se tem de outros textos/enunciados e com os que traz o autor. Compreender um texto é indicar o que tem a dizer em relação a ele e para ele; é, em certa medida, produzir um outro texto em resposta ao texto lido; é entrecruzar fios seus com os que traz o texto, tramando um outro que é, ao mesmo tempo, o mesmo, porque tem um autor, e outro, porque tem um leitor responsivo.

Percorridas essas questões, cabe ao professor dar subsídio aos alunos durante essa produção/construção de sentidos dos textos. Considerando que esses enunciados possuem formas variadas, há uma necessidade de se oferecer ao corpo discente um "leque" diversificado de textos a serem trabalhados e lidos, já que se espera que eles sejam leitores capazes de analisar criticamente os acontecimentos da realidade que os cerca. 
Todavia, o que acontece frequentemente no ensino de língua materna é a ênfase no aprendizado da leitura literária. Os alunos são apresentados a textos clássicos por meio do discurso do professor ou pelo material constituinte do livro didático, sendo que, na maioria dos casos, essa é a única referência que os estudantes terão daquela obra. Espera-se, ainda, que eles comentem, se posicionem, analisem determinada obra, sem que haja reais condições para que se realize esse processo. Assumindo a palavra de Bakhtin/Volochinov (1929 apud ROJO e JURADO, 2007, p.43), “[...] esse tipo de leitura, historicamente adotado pela escola, está centrado no reconhecimento/identificação das palavras e das ideias e não na sua compreensão ativa".

Além disso, é uma prática autoritária, já que o leitor está sujeito apenas a acatar o que o livro didático ou o professor propõe como forma de interpretação do texto, de forma que a bagagem cultural que o aluno carrega, a sua relação com textos anteriormente lidos e o conhecimento que ele possui desse contexto literário não são levados em consideração.

Há também a questão do ensino de leitura por meio da literatura, cuja função é o reconhecimento das características de determinada obra, buscando os elementos que a tornem condizentes com a escola literária a que pertenceu, assim como os seus personagens. Ainda nesse âmbito, é muito comum que se trabalhe com a fragmentação das obras literárias, buscando apenas atingir o objetivo citado acima. Nesse sentido, o trabalho de apreciar a obra, buscar interpretar o discurso do autor e sentir a poesia que a obra carrega acaba não ficando mais a cargo do aluno. Fruto dessa prática escolar, cria-se um leitor que não é capaz de estabelecer relações de sentido com o texto lido, que não tem autonomia para interpretar o que lê, apenas reproduzindo o que lhe é imposto.

Por fim, mesmo que ocorra a busca, nas salas de aula, por um cenário diferente desse apresentado, mesmo que se trabalhe o ensino da leitura na perspectiva dos gêneros textuais, o que geralmente ocorre na escola é a escolarização dos textos. O gênero é retirado da sua esfera de circulação/produção e levado para o ambiente escolar a fim de que se reconheçam os elementos que o constituem, a estrutura que ele carrega, e produzam-se novos textos, que desenvolvam capacidades leitoras específicas do letramento escolar, deixando de lado o entendimento da sua real função na sociedade.

\section{Princípios metodológicos}

A natureza qualiquantitativa da pesquisa é explicada à medida que a sua realização se deu através da aplicação de um instrumento de pesquisa, somado à análise dos dados levantados. Sendo assim, há de ser considerado que o instrumento utilizado consiste 
em um questionário, constituído por questões objetivas e subjetivas, sendo aplicado com uma turma do primeiro e outra do segundo ano do ensino médio, ambas pertencentes a uma escola pública da cidade de Joinville, com aproximadamente 25 alunos em cada.

O contato com a comunidade respondente ocorreu no ano de 2017, em paralelo com a disciplina de Estágio Curricular Supervisionado, constituinte da matriz dos anos finais do curso de Letras da Universidade da Região de Joinville (UNIVILLE). Seguindo essa lógica, além da aplicação do questionário, em função da documentação já existente para a atuação como estagiária, foi possível observar quinze aulas de Língua Portuguesa na instituição escolar, abrangendo turmas tanto do ensino fundamental quanto do médio. A ação nesse espaço possibilitou um olhar mais crítico, cujo resultado foi um subsídio maior para a discussão dos dados levantados.

\section{Análise e discussão dos dados}

Aproximadamente 34 sujeitos responderam ao instrumento de pesquisa, sendo eles alunos do $1^{\circ}$ e $2^{\circ}$ ano do ensino médio, possuindo em média de 9 a 10 anos de escolarização e de contato com a língua materna. Nesse sentido, os resultados serão discutidos em três seções diferentes.

\subsection{As metodologias e estratégias utilizadas pelo professor para desenvolver o trabalho com os gêneros textuais no ensino de Língua Portuguesa}

Na primeira seção, serão discutidas as questões 1 e 8 , as quais objetivaram identificar quais metodologias e estratégias são utilizadas durante as aulas de Língua Portuguesa para o trabalho com os gêneros textuais. A primeira busca verificar o entendimento dos respondentes acerca da relação existente entre os gêneros e os quatro eixos de ensino como um todo, enquanto a segunda volta o seu olhar para o ensino da gramática, indagando como esta é trabalhada durante o andamento das aulas.

No que concerne ao primeiro questionamento, a pergunta era de caráter objetivo, possuindo cinco alternativas como opção de resposta, mas que deveria ser respondida com apenas uma. Sendo assim, a questão se projeta da seguinte maneira: "Você acredita que as aulas de Língua Portuguesa são mais voltadas para:"; e carrega como opções de escolha as assertivas: a) A resolução de exercícios dos diversos conteúdos gramaticais; b) $O$ desenvolvimento da oralidade através de apresentações orais, debates, seminários, etc.; c) A produção escrita de diversos tipos de texto; d) Desenvolver o gosto/ hábito pela leitura; e) A mistura de todos os itens anteriores. 
A maior parte dos respondentes (31) optou pela mesma resposta (a alternativa "e"), demonstrando que as aulas de Língua Portuguesa, ministradas no contexto observado, correspondem a uma junção de todos os eixos de ensino para promover o desenvolvimento das competências linguísticas nos estudantes.

Há de ser considerado que as respostas atribuídas à primeira questão expõem uma postura esperada dos professores de língua. Especificando, os documentos oficiais de educação, particularmente a BNCC (2018), sugerem o trabalho com a articulação dos eixos de ensino em detrimento da sua fragmentação; e, ao mesmo tempo, o texto deve ser tomado como instrumento desses eixos, dando continuidade ao que fora idealizado anteriormente para o ensino de Língua Portuguesa.

Adentrando em um eixo mais específico, outra questão do instrumento de pesquisa tratava de investigar como ocorre o ensino da gramática: "Comente sobre como a gramática é ensinada pelo professor durante as aulas de Lingua Portuguesa". Por ser uma questão aberta e que, então, permite trabalhar com as percepções individuais de cada um dos sujeitos em aprendizagem, as respostas, em sua maioria, divergiram muito, mas, simultaneamente, encontraram pontos de semelhança.

Dentre as 34 respostas para a pergunta em questão, apenas 19 foram validadas e passíveis de análise, uma vez que os outros 13 respondentes, possivelmente, não compreenderam o teor da pergunta e acabaram comentando e avaliando a forma como o professor leciona, expressando carinho e admiração pelo docente, ao invés de detalhar como as aulas de gramática são construídas no dia a dia: $\mathrm{O}$ aluno A respondeu: "A gramática é bem ensinada"; $\mathrm{O}$ aluno B afirmou que: "As explicações são bem diretas, além de serem divertidas, a gente aprende com diversão. Na minha opinião, o professor X é o melhor que já tive”.

Partindo para os resultados que subsidiam a análise, acresce mencionar que a maioria das respostas obtidas nessa questão destaca que o ensino da gramática é feito através de um processo de demonstração de erros gramaticais. Diante desse cenário, algumas respostas chamam a atenção: o aluno $\mathrm{D}$ informou que durante as aulas: "Corrigimos os erros juntos”; enquanto que o aluno E salientou que o docente: “[...] fala onde devemos acentuar, onde não devemos, pergunta se temos dúvidas”; já o aluno F completou dizendo que: "O professor, ele ensina a gente a achar onde tá o erro e onde precisa ter a gramática". Seguindo essa lógica, conforme mencionado no aporte teórico do presente artigo, e assumindo a posição de Mendonça (2007), nos últimos anos, as aulas de Língua Portuguesa que se ocupam do ensino dos conteúdos gramaticais vêm incorporando uma 
nova prática, a gramática contextualizada, cujo principal objetivo é ensinar a gramática por uma perspectiva diferente, a que parte do texto e de um contexto para analisar e refletir sobre determinada classe de palavra, regra gramatical ou estrutura linguística.

$\mathrm{Na}$ tentativa de legitimar esse discurso, faz-se necessário pontuar que os respondentes também destacaram que a gramática é ensinada através do texto. Dentre as repostas, as mais interessantes são: a do aluno G, informando que o professor: "[...] trabalhava muito com textos"; a do aluno $\mathrm{H}$, que se destaca ao alegar que o ensino é feito: "Por textos, notícia, lendo rótulo"; e a do aluno I, que também agrega ao colocar: "Através de texto". Quando os estudantes expõem essa percepção sobre as aulas, é possível compreender que o docente tenta trabalhar com a gramática contextualizada, fazendo uso, por vezes, dos gêneros textuais.

A gramática contextualizada é delimitada como uma "metodologia renovada no ensino de língua materna”, em que se trabalha com o texto na centralidade. No entanto, o que acontece e que também pode ser constatado através do primeiro conjunto de respostas analisado é a utilização do texto a serviço da gramática tradicional, já que se propõem exercícios de análise linguística de frases isoladas, sem um contexto de utilização real.

Desse modo, a segunda maior recorrência de respostas revela que a gramática é ensinada por uma sequência: primeiro a explicação do conteúdo no quadro, em segundo lugar o momento de exemplificação para facilitar o entendimento e, por último, há a resolução de uma bateria de exercícios retirados do livro didático, da internet, de produção própria do docente ou de concursos de provas de vestibular como fechamento. De acordo com essa abordagem, há pouco espaço para a reflexão e o entendimento sobre o uso real da língua.

Após sugerir que as aulas de gramática, segundo as respostas anteriores, são construídas na perspectiva da gramática contextualizada, talvez seja um equívoco trazer para reflexão a ideia de que esse novo conjunto de respostas revela que a gramática é ensinada a partir de uma perspectiva estrutural e pouco reflexiva. Contudo, não há como fugir desse tipo de reflexão, quando um dos respondentes enfatiza que: "O professor passa o conteúdo, faz explicação, dá exemplos e depois uma atividade".

Acerca do uso de abordagem estrutural no ensino de gramática, Antunes (2007, p.22-23) assinala: 


\begin{abstract}
A língua não pode ser vista tão simplesmente, como uma questão, apenas de certo e errado, ou como um conjunto de palavras que pertencem a determinada classe e que se juntam para formar frases, à volta de um sujeito e de um predicado. A língua é muito mais do que isso tudo. É parte de nós mesmos, de nossa identidade cultural, histórica, social. [...] É preciso reprogramar a mente de professores, pais e alunos em geral, para enxergarmos na língua muito mais elementos do que simplesmente erros e acertos de gramática e de sua terminologia.
\end{abstract}

Em síntese, apesar do embate entre as duas abordagens diferentes no ensino da gramática, provocado pela percepção de sujeitos distintos, o ponto crucial continua sendo a utilização dos gêneros textuais no ensino da gramática. Nessa perspectiva, a reflexão que fica é que os gêneros não são utilizados, dentro do contexto observado, e para além dele, com muita frequência e de forma significativa no ensino dos conteúdos gramaticais nas aulas de Língua Portuguesa, e essa afirmação se faz possível à medida que os estudantes não reconhecem esse uso, independentemente das metodologias e estratégias utilizadas, já que apontam apenas para o "uso do texto", deixando lacunas em aberto àquele que se propõe a investigar esse processo.

\title{
A abordagem dos gêneros textuais no ensino dos quatro eixos da Língua Portuguesa
}

Retomando a concepção trabalhada no aporte teórico, em que se fala que a dificuldade de situar a oralidade como um objeto de ensino/aprendizagem ainda é perceptível, já que não se sabe onde e como inserir atividades com os gêneros orais no ambiente escolar, esta seção encontra sua relevância ao discutir uma única questão do instrumento de pesquisa que trabalha justamente com esse eixo de ensino.

Levando em consideração que um dos eixos de ensino já foi abordado e que os demais serão trabalhados na seção seguinte, o foco da discussão que se inicia é analisar como a oralidade vem sendo trabalhada nas aulas de Língua Portuguesa, destacando, principalmente, quais os gêneros orais utilizados pelos docentes de língua para trabalhar com o ensino da oralidade na sua prática pedagógica. Seguindo essa linha, a questão em análise solicitava aos respondentes: "Escolha abaixo as alternativas que indiquem a forma como o professor trabalha com a oralidade nas aulas de Lingua Portuguesa". 
Assim sendo, o gráfico abaixo corresponde ao número de vezes que cada um dos gêneros foi citado como abordagens no ensino da oralidade.

Gráfico 1: Gêneros utilizados no ensino da oralidade

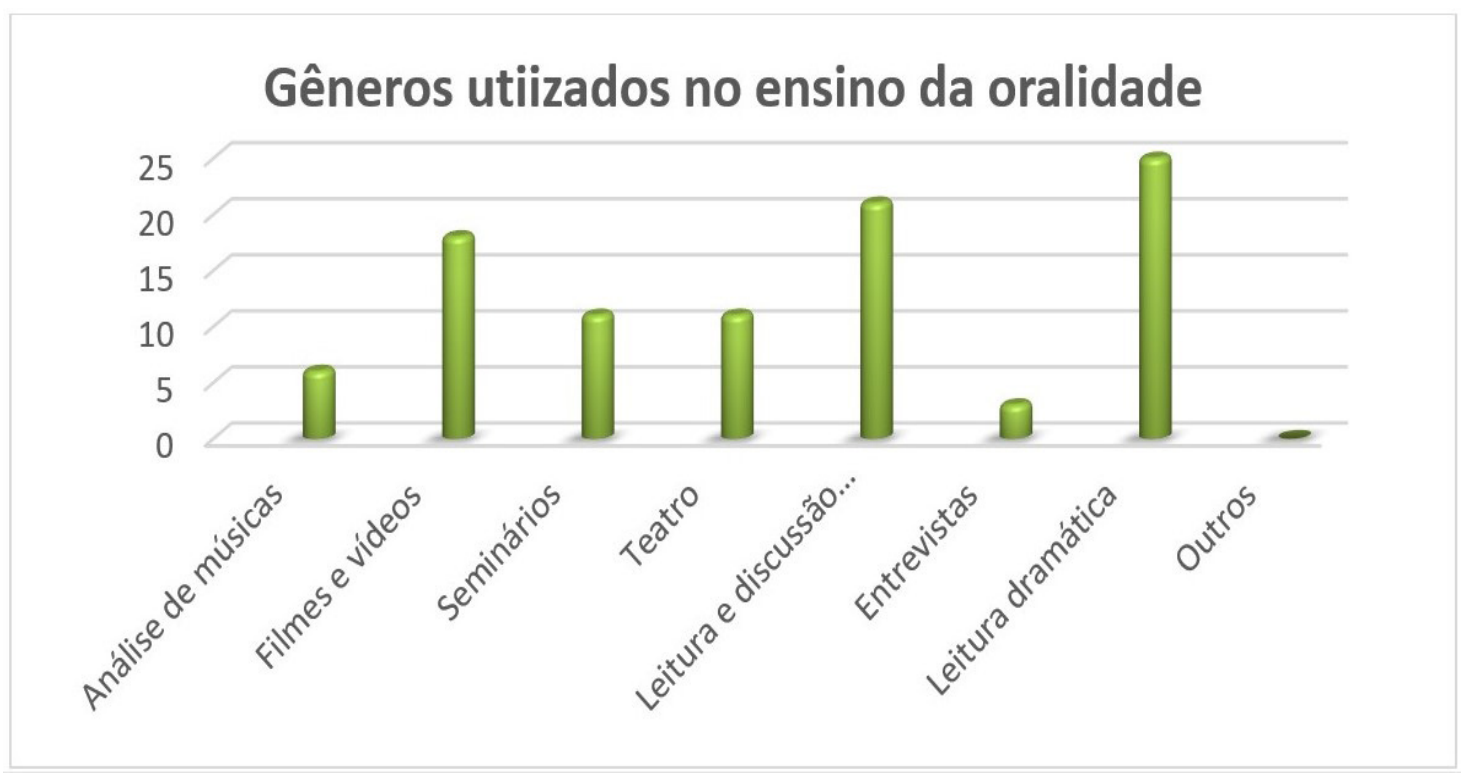

Fonte: Elaboração da autora, 2017.

Percebe-se que muitos gêneros foram escolhidos como abordagens do ensino da oralidade, demonstrando que, de fato, os gêneros orais vêm ganhando espaço nas aulas de Língua Portuguesa, mesmo que de maneira gradativa em comparação com os demais eixos, ou seja, a leitura, a gramática e a escrita.

Melo e Cavalcante (2007, p.182) trabalham com a ideia de que "[...] se o conhecimento linguístico, produção textual e leitura vão bem, o tratamento da oralidade no ensino de língua ganha menos importância”. Entretanto, os dados da referida questão em análise revelam, assim como citado anteriormente, que os docentes de língua vêm incorporando os quatro eixos no ensino da Língua Portuguesa, mesmo que uns se sobressaiam aos outros; os alunos reconhecem que seu aprendizado circula pelas quatro vertentes sugeridas como objetos de ensino dos documentos oficiais de educação.

Portanto, ainda que o trabalho com a oralidade demande novas estratégias e metodologias, há de se considerar que, em termos de ensino, os avanços foram muito grandes. Acresce enfatizar que, quando 34 sujeitos em aprendizagem listam mais de um gênero oral como uma abordagem do ensino da oralidade, possivelmente eles estão legitimando o que se espera para o ensino da Língua Portuguesa: o reconhecimento da oralidade e a abrangência dos quatro eixos na mesma medida. 


\section{O embate do reconhecimento do uso dos gêneros textuais nas aulas de Língua Portuguesa}

Na última seção, o objetivo é discutir um maior número de questões do instrumento de pesquisa, as de número 2, 3, 4, 5 e 6 . Novamente, há uma mistura entre questões objetivas e descritivas, que envolvem, particularmente, o uso dos gêneros textuais nos eixos da leitura e escrita. No que diz respeito à questão número dois, ela envolve o eixo da leitura e corresponde à seguinte pergunta: "Nas aulas destinadas à leitura são oferecidos mais de um tipo de texto para ser lido?"; possuindo duas opções como resposta: a) sim e b) não.

As respostas foram quase unânimes, sendo que 32 dos 34 respondentes optaram pelo sim. O objetivo da questão foi o de observar se os estudantes reconheciam que, além dos livros, eles também possuem outras opções de material para leitura, ou seja, os diferentes gêneros literários, publicitários, jornalísticos, quaisquer que sejam.

Os resultados foram bastante diversificados e correspondem ao gráfico a seguir:

Gráfico 2: Os gêneros mais lidos

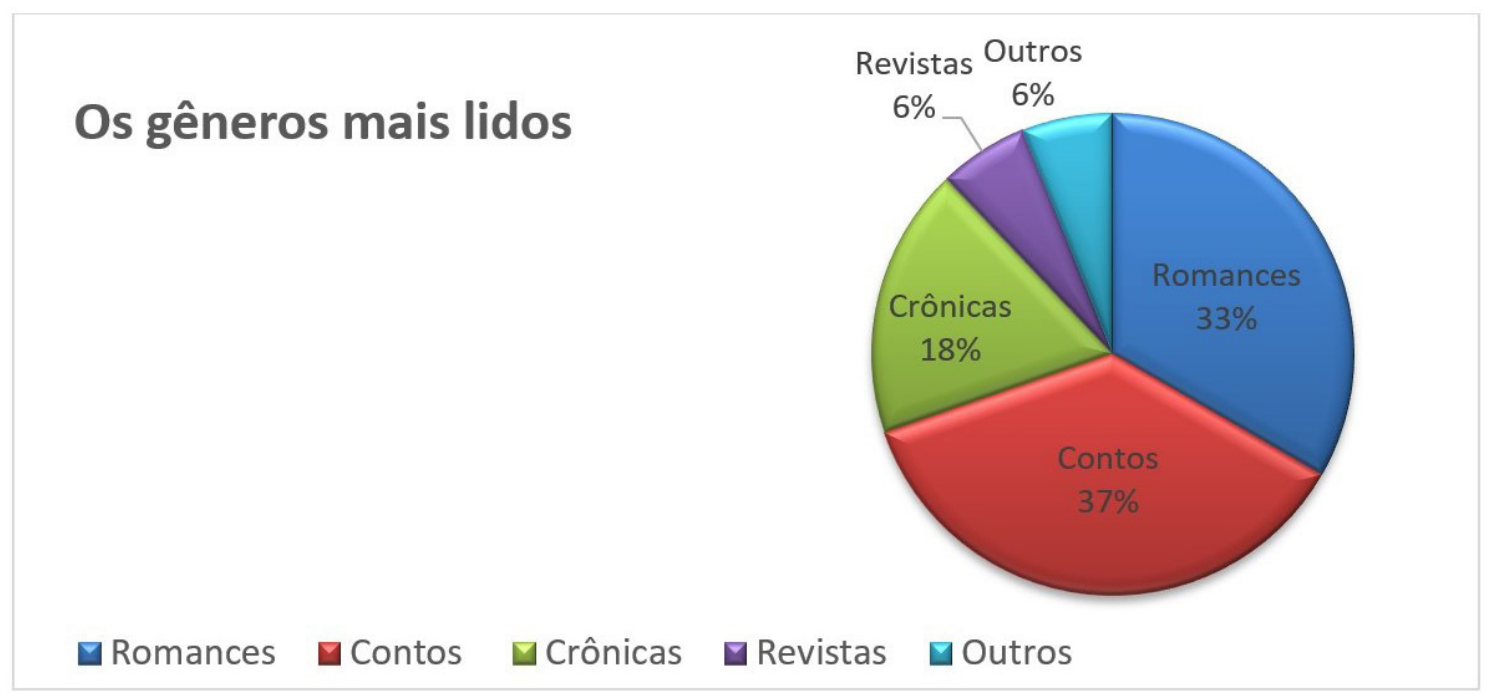

Fonte: Elaboração da autora, 2017.

Diante dos resultados, a questão proporciona duas vertentes diferentes de discussão. Primeiramente, fica nítido que, no espaço escolar e em especial nas aulas de Língua Portuguesa, muitas vezes, são os gêneros escolares ${ }^{2}$ clássicos, denominados por Dolz e Schneuwly (2004) como produtos culturais da escola, que são oferecidos para leitura e, em especial, os pertencentes à cultura do papel, resumindo-se a textos impressos e livros.

\footnotetext{
${ }^{2}$ Assumo a ideia de que os gêneros escolares são aqueles trabalhados e ensinados para terem sentido e função essencialmente no ambiente escolar e nas aulas de Língua Portuguesa.
} 
Analisando a representatividade que o gênero conto teve nos resultados da questão, pode-se dizer que, pelo fato de os estudantes estarem inseridos no âmbito escolar, em que é muito comum o trabalho com a fragmentação dos romances, o que não é recomendado e prejudica o processo de leitura, barrando o aluno a um conhecimento variado de obras literárias, muitos dos sujeitos em aprendizagem optam pela leitura dos contos por se tratar de um gênero sucinto, que permite a leitura na sua integridade.

Complementando, é interessante levar em consideração que, ao optarem pela leitura do gênero conto, os alunos contribuem para uma prática enriquecedora e que agrega muito às aulas de literatura, principalmente pelo fato de os docentes de Língua Portuguesa buscarem seguir as diretrizes dos documentos oficiais de educação (Proposta Curricular de SC, BNCC), as quais visam romper com a fragmentação no ensino de leitura e literatura. Logo, conforme já mencionado, um dos pontos positivos do trabalho com esse gênero é a facilidade no seu fluxo de leitura e compreensão, ou seja, por ser um texto curto, ele facilita o trabalho em sala de aula, principalmente por conta do tempo.

O segundo gênero mais mencionado, os romances, não revela grandes mistérios, já que é comum que os docentes incentivem a leitura de diversas obras e, pensando que as aulas de leitura no contexto observado são realizadas ao longo de todo o bimestre, se o aluno optar por esse gênero, consegue tranquilamente terminar a leitura de um romance inteiro.

Ademais, o outro ponto que merece destaque são as respostas que comtemplaram a opção "outros". Explicando melhor, alguns dos respondentes, além de marcarem como opção um dos gêneros disponíveis na questão, também responderam que costumam ler “poemas”. Assim sendo, há, de fato, o reconhecimento do uso dos gêneros durante as aulas de leitura, primeiramente porque o estudante cita o gênero poema e, em segundo lugar, porque, mesmo que ele não leia, possivelmente, fez menção ao gênero poema, pois recordou-se das aulas de Língua Portuguesa em que esse tipo de texto foi trabalhado, o que é bastante frequente nas duas fases de escolarização dos respondentes.

Atendo-me agora à questão de número 4, o foco de análise é modificado, uma vez que o olhar se volta ao eixo da escrita, buscando investigar como os alunos reconhecem o uso dos gêneros durante o processo de aprendizagem da língua escrita. Nesse sentido, foi perguntado aos estudantes: "Nas aulas de Língua Portuguesa, você costuma produzir por bimestre tantos tipos de texto ${ }^{3 \prime}$.

\footnotetext{
${ }^{3}$ Faço uso da expressão "tipos de texto" apenas para estar em concordância com o instrumento de pesquisa, em que não era recomendável utilizar o termo "gêneros textuais", já que os estudantes da educação básica não estão habituados com tal tipologia. Nesta questão, estou considerando a materialidade linguística, o texto produzido.
} 
Ao mencionar o vocábulo "bimestre", automaticamente o estudante está sendo convidado a uma reflexão acerca dos gêneros que o professor trabalhou em sala de aula, e, durante o período de observação das aulas de estágio, foi possível compreender que há uma preocupação em desenvolver as capacidades voltadas à produção de texto nos alunos, ou seja, há um trabalho constante com a produção de texto nas aulas de Língua Portuguesa, facilitando a resposta para essa questão. Novamente, como estratégia para apresentação dos resultados, recorro ao gráfico a seguir:

Gráfico 3: Número de textos produzidos por bimestre

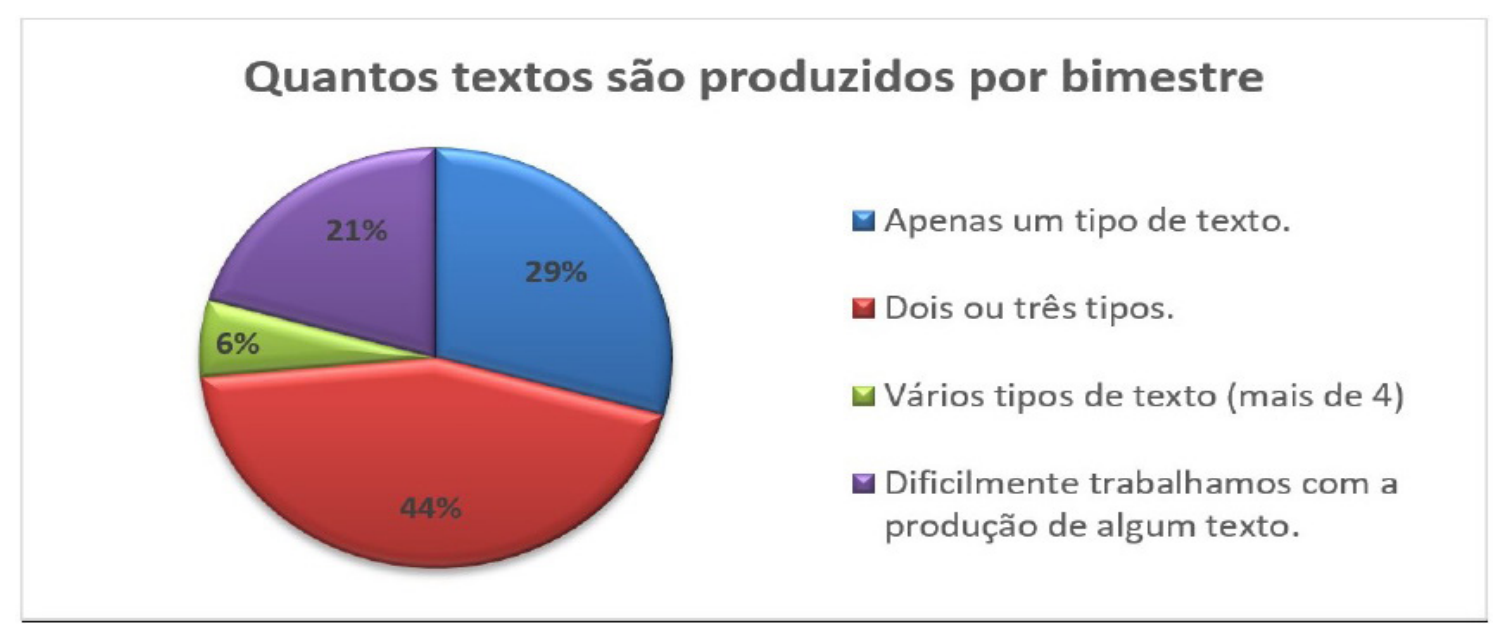

Fonte: Elaboração da autora, 2017.

Nota-se que aproximadamente $79 \%$ dos respondentes reconhecem o uso de diferentes tipos de texto durante o processo de aprendizagem da escrita, independentemente de assinalarem apenas um, dois ou três, ou quatro tipos de produção durante um bimestre de estudo, o que é bastante significativo para a pesquisa, demonstrando que o eixo em que mais se usa a variedade de textos é, de fato, a escrita. Entretanto, simultaneamente, $21 \%$ dos participantes da pesquisa não reconhecem a produção textual, já que apontam que não produzem nenhum tipo de texto durante as aulas ${ }^{4}$.

Frente a esses números, a reflexão que fica é de que, possivelmente, nas aulas de Língua Portuguesa do contexto observado, em algumas propostas de escrita, o gênero em si não ficou muito claro, deixando uma lacuna no entendimento da sua função enquanto texto comunicativo, da sua estrutura e do seu estilo.

\footnotetext{
${ }^{4}$ Os dados não indicam o reconhecimento do uso dos gêneros durante o processo de ensino e aprendizagem, mas também não negam a possibilidade.
} 
Mediante esse contexto, há de ser considerada, no ambiente escolar, mais precisamente nas aulas de Língua Portuguesa, a existência de produtores de textos experientes e iniciantes, justamente porque os alunos possuem práticas de letramento diferenciadas. Nesse sentido, em alguns casos, a aprendizagem da escrita ocorre sem muitos empecilhos e, em outros, há grandes dificuldades a serem vencidas. Segundo Silva e Melo (2007, p. 40): “[...] para produzir textos de boa qualidade, devemos possibilitar aos alunos aprenderem a comprometer-se mentalmente”.

Para tanto, o processo de escrita na escola deve ocorrer através de etapas. Lembrando que há diferentes níveis de conhecimento, os professores devem optar pelo uso do "passo a passo", assim, torna-se possível que todos os alunos acompanhem o objetivo proposto com um texto. Contudo, é importante ressaltar que ao docente cabe a função de mediador dessas etapas, já que:

Determinados aspectos do processo podem ser automáticos se um escritor é experiente, se tem familiaridade com o gênero que está produzindo. Em compensação, para os escritores iniciantes, os aspectos evidentes ou automatizados são escassos, e o professor deve fornecê-los. Por isso, é útil considerar o processo passo a passo (SILVA; MELO, 2007, p.39).

Além disso, seguindo com a análise do instrumento de coleta de dados, a questão a ser discutida é a de número 5, caracterizando-se como uma pergunta descritiva, envolvendo novamente as concepções individuais de cada um dos respondentes. Essa é, de longe, uma das questões mais importantes, pois investiga a percepção dos alunos acerca da importância de se trabalhar com os diferentes tipos de textos nas aulas de Língua Portuguesa, conforme segue: "Você considera importante e significativo que o professor ensine e solicite durante as aulas o trabalho com diferentes tipos de texto? Comente o que você acha desse jeito de dar aula".

Foi possível dividir os questionamentos em grupos de respostas semelhantes e, então, surgiram 6 pautas para colocar em discussão. A importância de trabalhar com diferentes tipos de texto foi relatada através dos seguintes aspectos: para estimular a criatividade; para o desenvolvimento da escrita; para aprender e conhecer diferentes tipos de texto; e para desenvolver o interesse pela leitura. E, em contrapartida, também havia respostas que sugeriam que o trabalho com a variedade de textos durante as aulas não é importante e que, quando se trabalha com muitos textos diferentes, gera-se uma confusão para o aprendizado dos alunos. 
Dialogando com a ideia de que aprender diferentes gêneros é importante para o desenvolvimento da escrita e da leitura, Todorov (1980 apud LEAL; MELO, 2007, p.49) pontua que os gêneros textuais possuem uma função prática tanto para os leitores, quanto para os que escrevem textos. No primeiro caso, eles servem como "horizontes de expectativas", ou seja, quando precisamos atingir um objetivo ou temos uma finalidade em determinada tarefa, lemos diferentes textos e bebemos de diversas fontes para escolhermos aquele que mais se aproxima do ideal para atender as nossas necessidades. Já para os escritores, sejam eles experientes ou iniciantes, esse fenômeno atua como "modelos de escrita”, pois, quando precisamos escrever determinado texto, buscamos, em nossa bagagem intelectual, os conhecimentos sobre a escrita e acerca das características dos textos que já conhecemos para facilitar o nosso trabalho.

Tendo em conta que a sociedade por onde circulamos e atuamos enquanto sujeitos é grafocêntrica, ou seja, é centrada na utilização da escrita, diferentemente das ágrafas, cuja comunicação se dá pela oralidade, é importante ressaltar que os sujeitos desse meio produzem muitos tipos de enunciados e, ao mesmo tempo, torna-se possível que eles reconheçam esses diferentes tipos de enunciados, agrupando-os pela sua semelhança ou pela sua diferença:

[...] Por estarmos inseridos no mundo da escrita, referimo-nos aos textos, categorizando-os, agrupando-os. [...] Somos capazes de atender a comandos de escrita de textos em que são indicados gêneros conhecidos, ou seja, nós interagimos através de gêneros e reconhecemos diferentes espécies de textos. [...] Assim, os grupos sociais, diante das diferentes situações de interação, criam formas de construir textos, que vão se consolidando e servindo como fonte de referência para a produção de novos textos, que precisem ser construídos em situações semelhantes àquelas (LEAL; MELO, 2007, p.17).

Igualmente, quando os respondentes mencionam que trabalhar com diferentes tipos de texto é importante para aprender e conhecer - como é o caso das respostas a seguir: "Sim, extremamente importante, pois ler e conhecer outros tipos de textos é muito significativo" (estudante J); "Acho importante para que o aluno conheça os diversos tipos de texto que existem" (estudante L) -, implicitamente, eles compreendem a relevância de aprender a variedade dos textos existentes na sociedade. O questionamento que fica é se esse movimento se dá, realmente, porque os estudantes reconhecem uma multiplicidade de textos nas diferentes esferas comunicativas, que transcendem o espaço escolar e circulam socialmente. 
É importante destacar que essa percepção não se constrói repentinamente, mas é um processo gradativo, o qual se inicia desde que cada criança realiza a sua entrada no mundo da escrita, mesmo que não seja alfabetizada.

Modificando um pouco o foco da análise, possivelmente, uma das repostas mais questionadoras foi a seguinte: "Bom, o professor passa até 3 tipos de texto, mas com essa quantia fica uma mistura que fica difícil compreender todos”. Apesar de estar relacionada com a questão anterior, em que foi tratada a quantidade de textos produzidos durante as aulas de Língua Portuguesa, essa resposta releva duas problemáticas: a) o aluno não consegue discernir um gênero do outro com muita clareza, atrapalhando a construção da sua bagagem cultural e linguística sobre os diferentes tipos de texto; e b) aparentemente, ele não demonstra enxergar muito sentido na sua aprendizagem.

Em uma última instância, coloco em discussão os gêneros mais produzidos nas aulas de Língua Portuguesa segundo os dados do instrumento de pesquisa. O gráfico abaixo representa, em média, quantas vezes cada um dos gêneros listados foi escolhido pelos respondentes:

Gráfico 4: Os gêneros mais produzidos nas aulas de LP

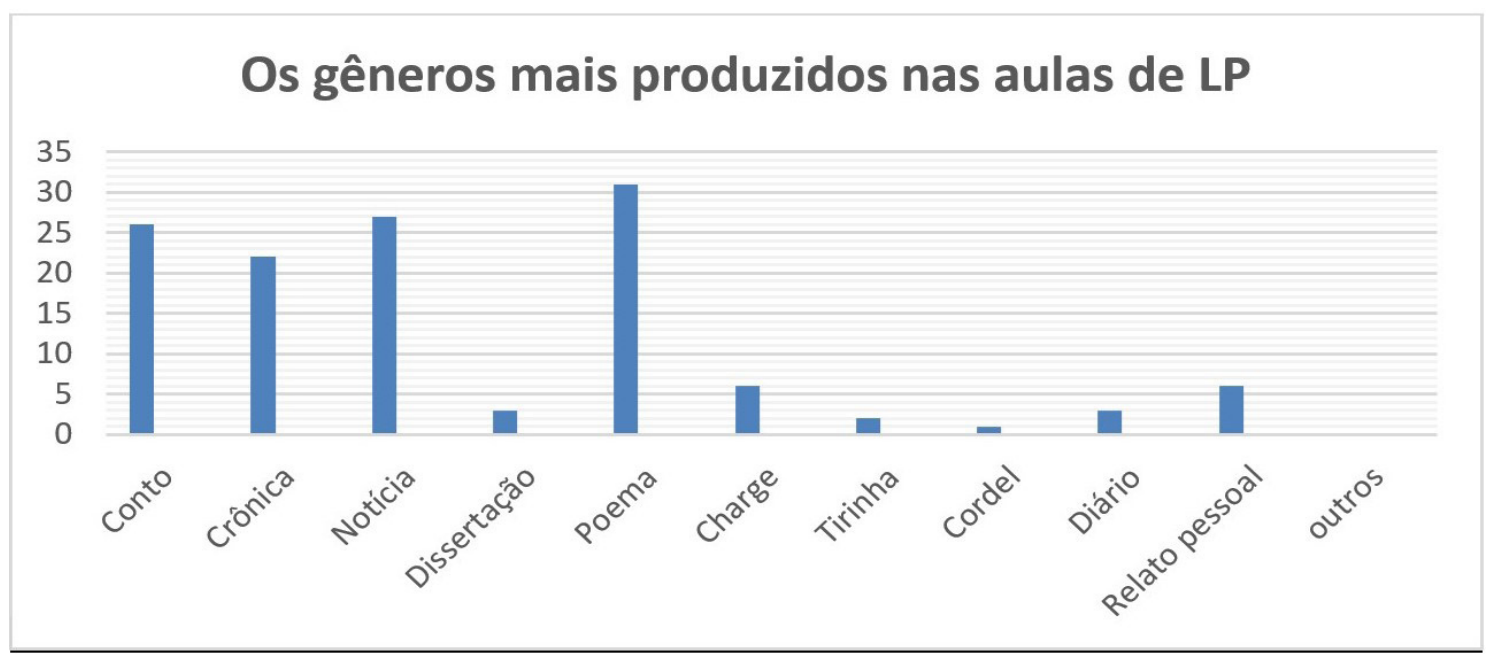

Fonte: Elaboração da autora, 2017.

É notável que os gêneros que mais se destacaram foram o poema, a notícia, o conto e a crônica, conhecidos como os tipos de textos essencialmente escolares. O reconhecimento desses gêneros por parte dos alunos pode estar entrelaçado à ideia de que esses textos são trabalhados em várias fases da escolarização, o que aumenta as chances de os sujeitos em aprendizagem tomarem noção da sua utilidade, características, estrutura e 
meio em que circulam. Ainda nesse âmbito, é indiscutível que, para enriquecer e tornar eficaz o ensino da escrita, os alunos não possam ter contato apenas com os gêneros tradicionais que cumprem as clássicas funções escolares, os quais são chamados por Dolz e Schneuwly (2004) de produtos culturais da escola.

Finalmente, segundo Leal e Melo (2007), nem sempre os professores que assumem uma turma possuem consciência da importância em dar uma sequenciação ao trabalho com a produção de textos e, por vezes, esquecem de oferecer aos estudantes a análise de textos que são úteis para além dos muros da escola, optando por oferecer os gêneros escolares, ou seja, aqueles que estão disponíveis no livro didático e que, aparentemente, são mais fáceis de ensinar.

\section{Palavras finais}

No corpus de análise, foi possível verificar que o ensino de Língua Portuguesa na perspectiva dos gêneros textuais tem ganhado as salas de aulas. Embora alguns anos tenham se passado desde que os PCN (1998) introduziram essa ideia na sociedade, hoje as suas raízes estão interiorizadas nos pressupostos de aprendizagem dos sujeitos atuantes em muitas instituições de ensino, mesmo que eles ainda não se deem conta de tal processo.

À vista disso, destaca-se o fato de que na contemporaneidade, a leitura, a produção escrita, a oralidade e análise linguística estão caminhando por um percurso trilhado há muito tempo. Essa fala se faz possível através do discurso dos próprios estudantes da comunidade respondente, que já reconhecem a importância de conhecer e aprender diferentes tipos de texto, independente do eixo de ensino em destaque na aprendizagem.

A culminância da pesquisa também contribuiu para um estudo acerca dessa área do ensino da Língua Portuguesa, de modo que foi possível: identificar se os quatro eixos de ensino são trabalhados na mesma proporção durante as aulas do contexto observado; reconhecer se ocorre, de fato, o trabalho com os gêneros textuais durante o ensino da leitura, da escrita, da oralidade e da gramática; e analisar se há o reconhecimento e a aceitação/o envolvimento dos alunos durante as aulas que envolvem o trabalho com os gêneros textuais. Nessa perspectiva, novas considerações acerca do funcionamento de cada um dos eixos de ensino foram construídas.

Assim sendo, foi evidenciado que alguns eixos de ensino trabalham mais com os gêneros textuais do que outros. Pensando na escrita, através dos dados obtidos, pode-se dizer que há uma nítida predominância nesse eixo, uma vez que os sujeitos respondentes reconhecem a produção escrita com facilidade, destacando que o contato com a multi- 
plicidade de textos é importante para a construção de um processo de ensino/aprendizagem significativo. Outro fator importante acerca do ensino da escrita é a certificação da existência de um trabalho voltado aos gêneros escolares, sobretudo porque os dados sinalizam que são ensinados, preferencialmente, os gêneros textuais que possuem uma aplicabilidade maior dentro do próprio âmbito escolar e não para além dos muros da instituição escola.

O ensino da leitura também foi caracterizado como parâmetro no uso dos gêneros textuais. Além de os resultados do instrumento de pesquisa contribuírem para o entendimento de que há uma importância sendo dada para esse eixo, já que os estudantes salientam, através de suas falas, que, de fato, ocorre um trabalho voltado à política de formação de leitores, existe, simultaneamente, uma indicação de que são oferecidos diferentes gêneros, em especial os literários, durante as aulas voltadas para o desenvolvimento do hábito/gosto pela leitura, e os respondentes reconhecem, novamente, a multiplicidade de textos que existe nesse processo.

A oralidade, apesar de toda a problemática defendida por diferentes teóricos, que assinalam a dificuldade de se situar esse eixo na sala de aula, vem ganhando espaço nas aulas de Língua Portuguesa, pois, no contexto observado, diferentes gêneros orais foram apontados como metodologias utilizadas pelo professor de português durante a aprendizagem, enaltecendo a variação de gêneros textuais durante o desenvolvimento do ensino da Língua Portuguesa mais uma vez.

Em contrapartida, o ensino da análise linguística, conforme os dados indicam, ainda carrega princípios do tradicionalismo, da concepção estruturalista da língua. Ao mesmo tempo que os respondentes sugerem que os conteúdos gramaticais são ensinados através do texto, também é destacado que o ensino desse eixo é realizado por meio da análise de frases isoladas, em que os fatos linguísticos são observados sem muita significância real para os alunos. Sendo assim, é o eixo em que o trabalho com os gêneros textuais fica em déficit.

\section{Referências}

ANTUNES, I. Gramática: uma área de muitos conflitos. In: ANTUNES, I. Muito além da gramática: por um ensino de línguas sem pedras no caminho. São Paulo: Parábola Editorial, 2007, p.19-24.

BAKHTIN, M. Marxismo e filosofia da linguagem. 16. ed. São Paulo: Hucitec, 1929.

BAKHTIN, M. Os gêneros do discurso: problemática e definição. In: BAKHTIN, M. Estética da criação verbal. 2. ed. São Paulo: Martins Fontes, 1997, p.277-279.

BRASIL. Secretaria de Educação Fundamental. Parâmetros curriculares nacionais: terceiro 
e quatro ciclos do ensino fundamental: língua portuguesa. Brasília: MEC/ SEF, 1998.

BRASIL. Base Nacional Comum Curricular: educação é a base. Brasília: MEC, 2018.

BEZERRA, M. A. Ensino de língua portuguesa e contextos teórico-metodológicos. In: DIONISIO, A. P.; MACHADO, A. R.; BEZERRA, M. A. Gêneros textuais e ensino. 2. ed. Rio de Janeiro: Lucerna, 2002, p.39-50.

BUNZEN, C. Da era da composição à era dos gêneros: o ensino de produção textual no ensino médio. In: BUNZEN, C.; MENDONÇA, M. Português no ensino médio e formação do professor. 2.ed. São Paulo: Parábola Editorial, 2007, p.139-162.

DOLZ, J.; SCHNEUWLY, B. Gêneros orais e escritos na escola. Tradução e organização Roxane Rojo e Glaís Sales Cordeiro. Campinas: Mercado das Letras, 2004.

LEAL, T. F.; MELO, K. L. R. de. Produção de textos: introdução ao tema. In: LEAL, T. F.; BRANDÃO, A. C. P. Produção de textos na escola: reflexões e práticas no ensino fundamental. Belo Horizonte: Autêntica, 2007, p.11-28.

MARCUSCHI, L. A. Gêneros textuais: definição e funcionalidade. In: DIONISIO, A. P.; MACHADO, A. R.; BEZERRA, M. A. Gêneros textuais e ensino. 2. ed. Rio de Janeiro: Lucerna, 2002, p.19-38.

MELO, C. T.V; CAVALCANTE, M.C.B. Oralidade no ensino médio: em busca de uma prática. In: BUNZEN, C.; MENDONÇA, M. (orgs.) Português no ensino médio e formação do professor. 2. ed. São Paulo: Parábola Editorial, 2007, p.181-198.

MENDONÇA, M. Análise linguística: refletindo sobre o que há de especial nos gêneros. In: SANTOS, C. F.; MENDONÇA, M.; CAVALCANTE, M. C.B. Diversidade textual: os gêneros na sala de aula. Belo Horizonte: Autêntica, 2007, p.73-88.

ROJO, R.; JURADO, S. A leitura no ensino médio: o que dizem os documentos oficiais e o que se faz? In: BUNZEN, C.; MENDONÇA, M. Português no ensino médio e formação do professor. 2.ed. São Paulo: Parábola Editorial, 2007, p.37-56.

SILVA, A. da; MELO, K. L. R. de. Produção de textos: uma atividade social e cognitiva. In: LEAL, T. F.; BRANDÃO, A. C. P. Produção de textos na escola: reflexões e práticas no ensino fundamental. Belo Horizonte: Autêntica, 2007, p.29-44.

TODOROV, T. Os gêneros do discurso. Trad. Elisa Angotti Kossovitch. São Paulo: Martins Fontes, 1980.

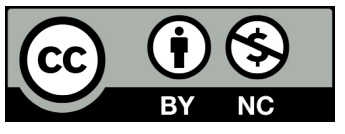

Data de submissão: 17/12/2019

Aceito em: $12 / 03 / 2020$ 